\title{
Coagulation screen is more specific than the anticardiolipin antibody ELISA in defining a thrombotic subset of lupus patients
}

\author{
RONALD H W M DERKSEN,' PAULA HASSELAAR, 13 LAYA BLOKZIJL.13 \\ FRITS H J GMELIG MEYLING, ${ }^{2}$ AND PHILIP G DE GROOT \\ From the Departments of 'Internal Medicine (Division of Immunopathology), 'Clinical Immunology, and \\ ${ }^{3}$ Hematology, University Hospital, Utrecht, The Netherlands
}

SUMmARY In 111 lupus patients we compared the potential of the IgG and IgM anticardiolipin antibody (ACA) enzyme linked immunosorbent assay (ELISA) and four different lupus anticoagulant (LAC) assays (partial thromboplastin time (PTT) of a 1:1 mixture of patient and control plasma with phospholipids from animal (PTT-st) or human brain (PTT-HB); PTT with $\vec{z}$ dilutions of human brain phospholipids (PL dilution); and kaolin clotting time of mixtures of patient and control plasma (KCT)) to identify patients with thrombosis $(26 / 111)$, fetal loss $\vec{\bullet}$ $(19 / 46)$, and/or thrombocytopenia (11/106). The highest specificity for thrombosis $(87 \%)$ was $\infty_{\infty}^{\infty}$ found with PTT-HB and PL dilution (sensitivity $65 \%$, detection rate $61 \%$ ); for fetal loss $(93 \%)$ ) with PL dilution (sensitivity $47 \%$; detection rate $82 \%$ ), and for thrombocytopenia $(83 \%)$ with KCT (sensitivity $82 \%$; detection rate $36 \%$ ). Compared with LAC assays, the sensitivity of ACAELISA was high $(\geqslant 77 \%)$, but specificity $(\leqslant 51 \%)$ and detection rate $(\leqslant 52 \%)$ were low. So, a panel of three LAC assays (PTT-HB, PL dilution, and KCT) can identify lupus patients $\frac{\mathscr{Q}}{\mathbb{Q}}$ apparently at risk for thrombosis, fetal loss, and/or thrombocytopenia, whereas the ACA-ELISA is insufficiently specific.

Key words: lupus anticoagulant, systemic lupus erythematosus.

Several recent studies have shown that the presence of circulating antiphospholipid (anti-PL) antibodies, (notably lupus anticoagulant (LAC) or anticardiolipin antibodies (ACA), or both) in lupus patients is associated with a high prevalence of thrombosis, fetal loss, and/or thrombocytopenia. ${ }^{1-6}$ These antibodies are not specific for lupus as they have been described in otherwise healthy individuals, in association with certain drugs, and in patients with other autoimmune diseases, malignancies, or infections. ${ }^{4-8}$ Lupus anticoagulant has been defined as immunoglobulins that interfere with phospholipid dependent coagulation tests without inhibiting the activity of specific coagulation factors. ${ }^{9}$ Initially, tests for LAC focused on the effects of tissue thromboplastin dilution on the prothrombin time

Accepted for publication 2. Tctober 1987

Correspondence to Dr Ronald il W M Derksen, Department of Internal Medicine, University Hospital, Catharijnesingel 101, 3511 GV Utrecht, The Netherlands.
(PT) because previous investigators had found that the most specific effect of anti-PL antibodies was to block the activation of prothrombin by the prothrombin activator complex of factors Xa, V, calcium, and phospholipids. "1" Subsequently it was 음 shown that the (activated) partial thromboplastin $D$ time ((A)PTT) was more sensitive for LAC than the PT. A prolongation in the (A)PTT that is not $N$ correctable by 1:1 mixing with normal sera indicates the presence of LAC, provided that activities of individual coagulation factors are normal." $11-13 \mathrm{~N}$ Influences of the source ${ }^{14} 1.5$ and concentration $^{91} 11^{16-19}$ of phospholipids on the results of phospholipid dependent coagulation assays have $\mathbb{\varnothing}$ been recognised, however. Exner et al described $\stackrel{\oplus}{+}$ characteristic patterns in the kaolin clotting time $\frac{7}{7}$ (KCT) assay when LAC positive and control plasmas

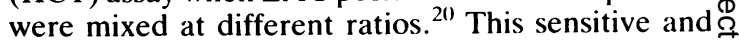
specific LAC assay overcomes possible masking $\mathbb{Q}$ effects of exogenous phospholipids. Recently, Branch et al described an enzyme linked immunosorbent 
assay (ELISA) with partial thromboplastin derived from human brain as an antigen, which enables detection of LAC in serum. ${ }^{21}$ At present there is uncertainty as to the best test for detecting LAC. ${ }^{9} \quad 16-22$

The association between LAC and biological false positive tests for syphilis on one hand and data indicating that cardiolipin is the principal antigen in these precipitation tests on the other, led to the introduction of solid phase immunoassays with cardiolipin as an antigen. ${ }^{123}$ Since the demonstration that raised ACA levels correlate both with LAC and with a history of thrombosis, fetal loss, and thrombocytopenia ${ }^{1624}$ the ACA-ELISA is widely used. Studies on differences between various anti-PL antibody assays with respect to their potential for identifying patients with particular clinical features are rare. ${ }^{25}$ Therefore, we compared in 111 patients with systemic lupus erythematosus (SLE) or lupus-like disease, the sensitivity, specificity, and detection rate of four different LAC assays, the ACA-ELISA, and combinations of these with respect to recognition of the subset of patients with thrombosis, fetal loss, and/or thrombocytopenia.

\section{Patients and methods}

\section{PAT IENTS}

One hundred and clzven patients (97 with SLE according to American Rheumatism Association (ARA) criteria ${ }^{26}$ and 14 with signs and symptoms compatible with SLE but meeting less than four ARA criteria for the diagnosis (lupus-like disease)), seen consecutively at the University Hospital, Utrecht, The Netherlands, were studied. There were 96 women and 15 men with a median age of 31 years (range 15-71) and median duration of disease of 7 years (range $0 \cdot 1-29$ ). Twenty six patients had a history of thromboembolic manifestations. These included deep venous thrombosis of the legs (DVT; $n=7$ ); DVT and pulmonary emboli $(n=3)$; DVT and cerebral infarction $(n=4)$; DVT and central retinal artery thrombosis $(n=1)$; DVT and thrombosis of digital arteries $(n=1)$; DVT and transient ischaemic attacks $(n=1)$; thrombophlebitis migrans $(n=1)$; thrombophlebitis and central retinal artery thrombosis $(n=1)$; pulmonary emboli $(n=2)$; amaurosis fugax $(\mathrm{n}=1)$; amaurosis fugax and transient ischaemic attacks $(n=1)$; thrombosis femoral artery, renal artery, and cerebral infarction $(n=1)$; cerebral infarction $(n=1)$; and central retinal artery thrombosis $(n=1)$. In one patient DVT had occurred postpartum. None of the thromboembolic episodes had occurred in a postoperative period. Forty six patients had a history of at least one pregnancy, and 19/46 had a history of fetal loss. The total number of pregnancies was 105 . Of these, 66 ended with live births (in 38 women), 12 with first trimester abortion (in seven women), and 27 with second or third trimester fetal death (in 14 women). None of the patients had a bleeding tendency.

\section{S A M P LES}

Blood samples for coagulation studies were obtained by venipuncture and collected into plastic tubes containing $3 \cdot 8 \%$ trisodium citrate $(0 \cdot 129$ $\mathrm{mol} / \mathrm{l})$ as the anticoagulant in a ratio of one part of anticoagulant to nine parts of blood. The samples were centrifuged at $4^{\circ} \mathrm{C}$ and $3000 \mathrm{~g}$ for $2 \times 10$ minutes to obtain platelet-poor plasma.

Blood samples for serum tests were obtained by venipuncture and collected into glass tubes without anticoagulants, at the same time as the platelet-poor plasma samples were drawn. The blood was allowed to clot at room temperature and then centrifuged at $175 \mathrm{~g}$ for 10 minutes to obtain serum.

Both platelet-poor plasma and serum were stored in small aliquots at $-80^{\circ} \mathrm{C}$ until use. None of the patients was treated with heparin at the time of blood sampling.

Normal control blood samples were taken from healthy hospital workers with a median age of 29 years (range 23-46).

ASSAYS FOR LUPUS ANTICOAGULANT PTT system with partial thromboplastin derived from animal (monkey and rabbit) brain (PTT-st)

Test plasma $(0.05 \mathrm{ml})$ was mixed with $0.05 \mathrm{ml}$ control plasma in a glass tube (at $\left.37^{\circ} \mathrm{C}\right)$. Immediately after mixing $0 \cdot 1 \mathrm{ml}$ commercial PTT reagent derived from monkey and rabbit brain (Boehringer, Mannheim, FRG) was added, mixed, and incubated for three minutes at $37^{\circ} \mathrm{C} . \mathrm{CaCl}_{2}$ $25 \mathrm{mmol} / \mathrm{l}(0 \cdot 1 \mathrm{ml})$ was then added and the clotting time was measured in duplicate (tilt tube method). A prolongation of the PTT by more than five seconds above that of pooled control plasma tested simultaneously indicated the presence of LAC. The normal value with pooled control plasma was 35 (5) $s$ (mean (2SD) of 50 tests).

\section{PTT system with partial thromboplastin derived from human brain (PTT-HB)}

A partial thromboplastin was prepared in our laboratory according to the method of Hjort et al, ${ }^{27}$ using human crude brain extract. Test plasma $(0.05 \mathrm{ml})$ was mixed with $0.05 \mathrm{ml}$ control plasma in a glass tube at $37^{\circ} \mathrm{C}$. Immediately after mixing $0 \cdot 1 \mathrm{ml}$ of the PTT reagent (stock solution diluted 1:100 in Michaelis acetate-veronal buffer solution) was added and incubated for eight minutes at $37^{\circ} \mathrm{C}$. $\mathrm{CaCl}_{2} 25 \mathrm{mmol} / \mathrm{l}(0 \cdot 1 \mathrm{ml})$ was then added and the 
clotting time measured in duplicate (tilt tube method). A prolongation of the PTT by more than 10 seconds above that of pooled control plasma tested simultaneously indicated the presence of LAC. The normal value with pooled control plasma was $55(10) \mathrm{s}$ (mean (2SD) of 50 tests).

\section{Phospholipid dilution test (PL dilution)}

The PTT of test plasma was measured as described above with different dilutions (Michaelis acetateveronal buffer solution) of the stock solution derived from human brain $(1: 100 ; 1: 175 ; 1: 250)$. With pooled control plasma the PTT increased $5(8)$ s (mean (2SD) of 50 tests) on dilution of the reagent from 1:100 to $1: 250$. The presence of more than 13 seconds increase with test plasma (all clotting times measured in duplicate) indicated the presence of LAC.

\section{Kaolin clotting time (KCT)}

Test and control plasma were mixed at $37^{\circ} \mathrm{C}$ at different ratios $(0,25,50,75,100 \%$ test plasma $)$ in plastic tubes. ${ }^{17}$ Immediately after mixing $0.1 \mathrm{ml}$ of the mixtures was incubated with $0.05 \mathrm{ml}$ kaolin $(20 \mathrm{mg} / \mathrm{ml}$ Michaelis acetate-veronal buffer solution) for three minutes at $37^{\circ} \mathrm{C}$. $\mathrm{CaCl}_{2} 25 \mathrm{mmol} / \mathrm{l}(0 \cdot 1 \mathrm{ml})$ was added and the time to clot formation accurately measured in duplicate on an automated coagulometer (KC10; Amelung $\mathrm{GmbH}$, Lieme, West Germany). Results were expressed as a KCT index according to the formula described by Rosner et al. ${ }^{28}$

$$
\underline{\text { (KCT 1:1 mixture) })-(\text { KCT control plasma })} \times 100 \%
$$

(KCT test plasma)

In healthy controls $(n=42)$ an index of $5(12)$ (mean (2SD)) was calculated. Values above 17 indicated the presence of LAC.

ANTIBODIES TO CARDIOLIPIN

Twenty five microlitres of a solution of cardiolipin (Sigma, St Louis, Mo, USA; $48 \mu \mathrm{g} / \mathrm{ml}$ ethanol 70\%) was added to 96 well polyvinyl assay plates (Costar, Cambridge, MA, USA) and the cardiolipin coated on the surface by evaporation under nitrogen within six minutes. The uncoated area was blocked by addition of $150 \mu \mathrm{l}$ of phosphate buffered saline (PBS) containing $10 \%$ fetal calf serum (FCS) for two hours at room temperature, washed three times with PBS, and then $50 \mu \mathrm{l}$ of 1:32 and 1:256 dilutions (in $\mathrm{PBS} / 10 \% \mathrm{FCS}$ ) of test serum was added in duplicate. The 1:32 dilution was chosen because in introductory experiments it provided the best discrimination between the average 'background' values of a cohort of 40 sera from apparently healthy volunteers and the values of 12 patients' sera. A serum from a patient highly positive for both IgGACA and IgM-ACA, prediluted $1: 4$, served as a $\vec{F}$ standard. This standard sample was diluted doubly from $1: 32$ to $1: 1024$ in PBS/10\% FCS. Fifty microlitres of each of these six dilutions was added in $\frac{\overline{5}}{\bar{n}}$ duplicate to each plate to create a standard curve. $\vec{\nabla}$ Furthermore, $50 \mu \mathrm{l}$ pooled control serum (diluted $\stackrel{\varnothing}{\circ}$ $1: 32$ and $1: 256)$ was added to each plate as was $50 \mu \mathrm{l}$ के $\mathrm{PBS} / 10 \%$ FCS to blank control wells.

After incubation for one hour at room temperature the plates were washed three times with PBS. $\vec{\omega}$ Alkaline phosphatase conjugated antibodies (goat antihuman IgG or IgM alkaline phosphatase; Tago, Burlingame, CA, USA) were diluted in $\mathrm{PBS} / 10 \%$ FCS (1:2000 for IgG; 1:1500 for IgM) and $50 \mu \mathrm{l}$ was ir added to each well. After incubation for three hours $\omega_{\sigma}$ at room temperature the plates were washed again + with PBS. Then $100 \mu \mathrm{l}$ substrate $(0.6 \mathrm{mg} p$-nitro- 을 phenyl phosphate/ml diethanolamine buffer $\mathrm{pH} 9.8 \overrightarrow{-}$ (Sigma, St Louis, Mo, USA)) was added. After 15 minutes' incubation at room temperature the reaction was stopped by addition of $50 \mu \mathrm{l} 2.4 \mathrm{M} \vec{\varnothing}$ $\mathrm{NaOH}$. Colour development was read at $405 \mathrm{~nm}$ in a Titertek multiscan photometer (Flow Laboratories, Finland). The absorbance at the 1:32 dilution of the standard sample was chosen arbitrarily as indicating the presence of 100 units of ACA. The absorbance read for the other samples was expressed as units $\varnothing$ using the computed standard curve. A positive $\vec{F}$ result indicates a value in units more than 2SD (71 웅 apparently healthy volunteers tested on six different occasions) over the value obtained with pooled control serum. Positive results were graded according to criteria agreed upon at the international workshop on standardisation of the ACA assay in London $^{29}$ : for IgG ACA low positive (mean (2SD) units $<80)$; medium positive $(80<$ units $<185)$; high $ᄋ$ positive (units $>185$ ); for IgM ACA low positive $₹$ (mean $(2 \mathrm{SD})<$ units $<25)$; medium positive $(25<$ 응 units $<200$ ); high positive (units $>200$ ).

Intra-assay coefficients of variation, obtained by testing four dilutions of the standard sample (ACA $\tilde{N}$ levels of these dilutions covered the entire range of the assay) on the same plate 12 times, were found to $\mathrm{N}$ be $6.4 \%, 7.1 \%, 3.4 \%$, and $3.1 \%$ for IgG ACA and $10 \cdot 6 \%, 9 \cdot 0 \%, 4 \cdot 4 \%$, and $4 \cdot 8 \%$ for IgM ACA. Interassay coefficients of variation expressed in units 6 were calculated from 10 different assays during a period of two months. These were $14.8 \%, 9.5 \%, \stackrel{?}{?}$ $10.4 \%$, and $5.3 \%$ for IgG ACA and $14.6 \%, 10.2 \%$, $8.6 \%$, and $7 \cdot 4 \%$ for IgM ACA.

PLATELET COUNTS

Blood platelets were counted in edetic acid-blood by the Coulter counter method. 


\section{CALCULATIONS}

The $\chi^{2}$ test was used for statistical analysis. For evaluation the following definitions were used $^{30}$ : sensitivity - the probability that the test result will be positive when the patient has the particular symptom, or (true positive/(true positive + false negative) $\times 100 \%$; specificity - the probability that the result will be negative when the symptom is not present, or (true negative/(true negative + false positive) $) \times 100 \%$; detection rate-the probability that the particular symptom will be present when the test result is positive, or (true positive/(true positive+ false positive) $) \times 100 \%$.

\section{Results}

PREVALENCE OF ANTI-PL ANTIBODIES

In $47 / 111$ patients at least one LAC assay was positive. Four positive LAC assays were found in 19 patients and three positive assays in seven patients (PL dilution negative $(n=3)$, KCT negative $(n=2)$, PTT-HB negative $(n=1)$, PTT-st negative $(n=1))$. In five patients two LAC assays were positive (PTTHB and PTT-st $(n=2)$, PTT-HB and PL dilution $(\mathrm{n}=1)$, PTT-st and KCT $(\mathrm{n}=1)$, PTT-st and PL dilution $(n=1))$, and in 16 patients only one assay was positive (PTT-st $(n=13)$, PL dilution $(n=3)$ ). Prevalences of a positive PTT-st, PTT-HB, PL dilution, and $\mathrm{KCT}$ were $38 \%, 25 \%, 25 \%$, and $23 \%$ respectively.

Raised levels of IgG ACA were found in 63/111 patients. Most of these (51/63) were low positive; $8 / 63$ were medium, and $4 / 63$ high positive. Raised levels of IgM ACA were found in 63/111 patients. Of these, $47 / 63$ were low positive; 14/63 medium, and $2 / 63$ high positive.
INTERASSAY CORRELATIONS

There was a significant relation between the results of the LAC assays (Table $1 ; \mathrm{p}<0 \cdot 0005$ ). Raised levels of IgG ACA showed a significant relation with LAC detected in any assay (Table $1 ; \mathrm{p}<0.05$ ). Raised IgG ACA levels were present in 29/42, $23 / 28,25 / 28$, and $22 / 25$ patients with a positive PTTst, PTT-HB, PL dilution or KCT respectively. Of the 12 sera that were medium or high positive for IgG ACA, seven were positive in all LAC assays; one was positive in all LAC assays except for PL dilution; two were positive for PL dilution only, and two were negative in all LAC assays. No significant relation was found between raised levels of IgM ACA and LAC; however, raised levels of IgM ACA and IgG ACA were significantly related (Table 1; $\mathrm{p}<0.005)$.

RELATION BETWEEN ANTI-PL ANTIBODIES AND THROMBOSIS

Twenty six patients had a history of thrombosis. Of these, 12 patients were positive in all LAC assays, five were positive in three LAC assays (negative only with PTT-st $(n=1)$; negative only with PTT-HB $(n=1)$; negative only with PL dilution $(n=2)$; negative only with KCT $(n=1)$; one was positive in two LAC assays (PTT-HB and PL dilution); and one was positive only with PL dilution. In seven patients with a history of thrombosis all LAC assays were negative, and six patients with a history of thrombosis were negative for IgG ACA. Of the latter patients, four were negative in all LAC assays and two had four positive LAC assays. Five patients with a history of thrombosis were negative for IgM ACA. Of these, two were negative in all LAC assays and three had four positive LAC assays. Six out of

Table 1 Interassay correlations

\begin{tabular}{|c|c|c|c|c|c|c|}
\hline Assay & & $P T T-H B$ & PL dilution & $K C T$ & $\lg G A C A$ & $\operatorname{Ig} M A C A$ \\
\hline PTT-st & $\begin{array}{l}\chi^{2} \text { value* } \\
\text { p value }\end{array}$ & $\begin{array}{l}48 \cdot 193 \\
<5 \times 10^{-4}\end{array}$ & $\begin{array}{l}31 \cdot 250 \\
<5 \times 10^{-4}\end{array}$ & $\begin{array}{l}46.408 \\
<5 \times 10^{-4}\end{array}$ & $\begin{array}{l}4.159 \\
<5 \times 10^{-2}\end{array}$ & $\begin{array}{l}0.729 \\
\text { NS }\end{array}$ \\
\hline PTT-HB & $\begin{array}{l}\chi^{2} \text { value* } \\
\mathrm{p} \text { value }\end{array}$ & & $\begin{array}{l}64 \cdot 314 \\
<5 \times 10^{-4}\end{array}$ & $\begin{array}{l}76 \cdot 278 \\
<5 \times 10^{-4}\end{array}$ & $\begin{array}{l}9.832 \\
<5 \times 10^{-3}\end{array}$ & $\begin{array}{l}3.284 \\
\text { NS }\end{array}$ \\
\hline PL dilution & $\begin{array}{l}\chi^{2} \text { value* } \\
\text { p value }\end{array}$ & & & $\begin{array}{l}59.096 \\
<5 \times 10^{-4}\end{array}$ & $\begin{array}{l}16 \cdot 143 \\
<5 \times 10^{-4}\end{array}$ & $\begin{array}{l}1 \cdot 880 \\
\text { NS }\end{array}$ \\
\hline $\mathrm{KCT}$ & $\begin{array}{l}\chi^{2} \text { value* } \\
\text { p value }\end{array}$ & & & & $\begin{array}{l}12.833 \\
<5 \times 10^{-4}\end{array}$ & $\begin{array}{l}1.662 \\
\text { NS }\end{array}$ \\
\hline IgG ACA & $\begin{array}{l}\chi^{2} \text { value* } \\
\text { p value }\end{array}$ & & & & & $\begin{array}{l}10 \cdot 163 \\
<5 \times 10^{-3}\end{array}$ \\
\hline
\end{tabular}

*At $1 \mathrm{df}$.

Abbreviations: PTT-st $=$ partial thromboplastin time with a commercial partial thromboplastin derived from animal brain; PTT$\mathrm{HB}=$ partial thromboplastin time with a partial thromboplastin derived from human brain; $\mathrm{PL}=$ phospholipid reagent; KCT $=\mathrm{kaolin}$ clotting time; $\mathrm{ACA}=$ anticardiolipin antibodies. 
twelve and 9/16 patients with medium or high levels of IgG ACA and IgM ACA respectively did not have a history of thrombosis. In all patients with a history of thrombosis levels of protein $\mathrm{C}$, protein $\mathrm{S}$, and AT III were normal.

We found a significant relation between the presence of anti-PL antibodies, detected by any of the assays, and a history of thrombosis (Table $2 ; \chi^{2}$ value varying from 5.626 (IgG ACA; $p<0.025)$ to 29.618 (KCT; $\mathrm{p}<0.0005)$ ). Table 2 shows the sensitivity, specificity, and detection rate of the anti-PL antibody assays for thrombosis. LAC detected with PTT-HB or PL dilution had the combination of a relatively high sensitivity $(65 \%)$, specificity $(87 \%)$, and detection rate $(61 \%)$. For both IgG-ACA and IgM-ACA high sensitivities were found $(\geqslant 77 \%)$, but specificities $(\leqslant 51 \%)$ and detection rates $(\leqslant 33 \%)$ were low.

RELATION BETWEEN ANTI-PL ANTIBODIES AND FETAL LOSS

For the 46 women studied with at least one pregnancy, the total number of pregnancies was 105. There was a total of 39 fetal losses (in 19 women). Of these, 12 had occurred in seven women positive for all LAC assays; six in two women positive in all LAC assays except for PL dilution; five in one woman positive in all assays except for KCT, and four in one woman positive for all LAC assays except for PTT-st. Ten fetal losses had occurred in $\underset{\mathcal{S}}{ }$ six women negative in all LAC assays, and two ino two women who were positive for LAC in one assay only (PTT-st). Raised levels of IgG ACA were $\frac{\bar{s}}{\circ}$ found in $31 / 46$ patients (medium or high levels in $\frac{\mathbb{}}{\triangle}$ six) and raised IgM ACA levels in 28/46 (medium or क high levels in six).

Except for raised IgM ACA, there was a signifi- $\vec{\circ}$ cant relation between the presence of anti-PL $\overrightarrow{\vec{\omega}}$ antibodies and a history of fetal loss (Table 3$) \cdot \chi^{2} \stackrel{\omega}{\omega}$ Values varied from 4.166 (IgG ACA; $p<0.05)$ to 11.529 (PTT-HB; $\mathrm{p}<0 \cdot 001)$. LAC detected with PTT-HB had, compared with the other LAC assays, ir an intermediate sensitivity $(58 \%)$ together with a high specificity $(89 \%)$ and detection rate $(79 \%) \stackrel{\curvearrowright}{\oplus}$ (Table 3). The presence of raised ACA levels had a응 high sensitivity $(\geqslant 79 \%)$ associated with a low specificity $(44 \%)$ and detection rate $(\leqslant 52 \%)$. A 3 history of fetal loss was present in $3 / 6$ and $5 / 6 \stackrel{2}{2}$ patients with medium or high levels of IgG ACA $\overrightarrow{0}$ and IgM ACA respectively.

RELATION BETWEEN HISTORY OF FETAL

LOSS AND HISTORY OF THROMBOSIS

Ten out of 19 patients with a history of fetal loss also had a history of thrombosis, whereas $10 / 13$ patients

Table 2 Anti-PL antibody assays and history of thrombosis

\begin{tabular}{|c|c|c|c|c|c|}
\hline Assay & $\chi^{2}$ Value ${ }^{*}$ & p Value & $\begin{array}{l}\text { Sensitivity } \\
(\%)\end{array}$ & $\begin{array}{l}\text { Specificity } \\
(\%)\end{array}$ & $\begin{array}{l}\text { Detection rate } \\
(\%)\end{array}$ \\
\hline PTT-st & $8 \cdot 108$ & $<5 \times 10^{-3}$ & 61 & 69 & 38 \\
\hline PTT-HB & $29 \cdot 031$ & $<5 \times 10^{-4}$ & 65 & 87 & 61 \\
\hline PL dilution & $29 \cdot 031$ & $<5 \times 10^{-4}$ & 65 & 87 & 61 \\
\hline KCT & $29 \cdot 618$ & $<5 \times 10^{-4}$ & 61 & 69 & 64 \\
\hline IgG ACA & $5 \cdot 626$ & $<2.5 \times 10^{-2}$ & 77 & 49 & 32 \\
\hline IgM ACA & $7 \cdot 976$ & $<5 \times 10^{-3}$ & 81 & 51 & 33 \\
\hline
\end{tabular}

*At $1 \mathrm{df}$.

Abbreviations: see Table 1.

Table 3 Anti-PL antibody assays and history of fetal loss*

\begin{tabular}{|c|c|c|c|c|c|c|}
\hline Assay & & $\chi^{2}$ Valuet & p Value & $\begin{array}{l}\text { Sensitivity } \\
(\%)\end{array}$ & $\begin{array}{l}\text { Specificity } \\
(\%)\end{array}$ & $\begin{array}{l}\text { Detection rate } \\
(\%)\end{array}$ \\
\hline PTT-st & & $6 \cdot 377$ & $<2.5 \times 10^{-2}$ & 63 & 74 & 63 \\
\hline PTT-HB & & $11 \cdot 529$ & $<1 \times 10^{-3}$ & 58 & 89 & 79 \\
\hline PL dilution & & $9 \cdot 787$ & $<5 \times 10^{-3}$ & 47 & 93 & 82 \\
\hline KCT & & 9.483 & $<5 \times 10^{-3}$ & 53 & 89 & 77 \\
\hline IgG ACA & & $4 \cdot 166$ & $<5 \times 10^{-2}$ & 84 & 44 & 52 \\
\hline IgM ACA & & $2 \cdot 690$ & NS & 79 & 44 & 50 \\
\hline
\end{tabular}

*Forty six women with a history of pregnancy were evaluated. 
Table 4 Anti-PL antibody assays and presence of thrombocytopenia (platelets $<150 \times 10^{9} / l$ )

\begin{tabular}{lcllll}
\hline Assay & $\chi^{2}$ Value & $p$ Value & $\begin{array}{l}\text { Sensitivity } \\
(\%)\end{array}$ & $\begin{array}{l}\text { Specificity } \\
(\%)\end{array}$ & $\begin{array}{l}\text { Detection rate } \\
(\%)\end{array}$ \\
\hline PTT-st & $5 \cdot 999$ & $<2 \cdot 5 \times 10^{-2}$ & 73 & 61 & 16 \\
PTT-HB & $20 \cdot 527$ & $<5 \times 10^{-4}$ & 82 & 81 & 33 \\
PL dilution & $20 \cdot 527$ & $<5 \times 10^{-4}$ & 82 & 81 & 33 \\
KCT & $23 \cdot 094$ & $<5 \times 10^{-4}$ & 82 & 83 & 36 \\
IgG ACA & $2 \cdot 750$ & NS & 82 & 44 & 15 \\
IgM ACA & 1.299 & NS & 73 & 45 & 13 \\
\hline
\end{tabular}

${ }^{*}$ At 1 df.

Abbreviations: see Table 1.

with a history of both thrombosis and pregnancy had experienced fetal loss. The relation between these parameters was significant $\left(\chi^{2}=9 \cdot 483 ; p<0 \cdot 005\right)$.

RELATION BETWEEN ANTI-PL ANTIBODIES AND PRESENCE OF THROMBOCYTOPENIA Of the 106 patients studied, 11 had platelet counts below $150 \times 10^{9} / \mathrm{l}$ and four of these below $100 \times 10^{9} / 1$. Five of the 11 patients with thrombocytopenia were positive in all anti-PL antibody assays, three were positive in all assays except for IgM ACA, and one patient was negative for LAC with PTT-st and positive in all other anti-PL assays. Two patients were negative in all anti-PL assays except for IgM ACA.

A significant relation was found between presence of thrombocytopenia and a positive LAC assay. $\chi^{2}$ varied from 5.999 with PTT-st $(\mathrm{p}<0.025)$ to 23.094 with the KCT $(p<0 \cdot 0005)$ (Table 4). LAC detected with the KCT had the highest specificity $(83 \%)$; the detection rate of all assays was relatively low $(\leqslant 36 \%$ ) (Table 4).

RELATION BETWEEN THE PRESENCE OF THROMBOCYTOPENIA AND HISTORY OF THROMBOS IS

Eight of the 11 patients with thrombocytopenia had a history of thrombosis, whereas a history of fetal loss was present in five of the seven patients with thrombocytopenia who had been pregnant. The presence of thrombocytopenia was significantly related to a history of thrombosis ( $\chi^{2}$ 17.579; $\mathrm{p}<0.0005)$, but not to a history of fetal loss $\left(\chi^{2}=3 \cdot 616\right)$.

\section{Discussion}

Current data indicate that both $\mathrm{LAC}$ and raised ACA levels are markers of a subset of lupus patients with a high prevalence of thrombosis, fetal loss, and thrombocytopenia. ${ }^{1-6}$ Whereas ACA are uniformly detected by solid phase immunoassays, there are many coagulation assays to detect anti-PL antibodies. $^{9-2022}$ Both the presence of deficiencies or inhibitors of specific coagulation factors and heparin should be distinguished from LAC as the cause of an abnormal assay result. ${ }^{12-20} 22$ If control and test plasma are mixed before assessment of the clotting time and an incubation period is avoided, as we did in our assays, this usually prevents interference of coagulation factor deficiencies and inhibitors respectively in LAC assays. The presence of strong inhibitors of coagulation factors, however, cannot be excluded, unless specifically looked for in LAC positive samples. ${ }^{16} 1922$ Such strong inhibitors, however, are rare and are usually associated with a bleeding tendency. Heparin can be neutralised with protamine sulphate in case heparin is present in the test sample. ${ }^{19}$

With the PTT-st and PTT-HB assays we found a prevalence of LAC of $38 \%$ and $25 \%$ respectively. This difference is probably caused by differences in PL composition between the thromboplastins used. $^{14}{ }^{15}$ The prevalence of LAC defined with PL dilution and KCT was $25 \%$ and $23 \%$ respectively. The prevalence (57\%) we found for increased ACA serum concentrations is comparable with the $54 \%$ recently described in an unselected Swedish population of patients with SLE. ${ }^{31}$

Our data confirm the presence of a close relation between results of individual LAC assays, and between the presence of LAC and raised levels of IgG ACA. In our séries most LAC positive patients (69-89\%, depending on the assay used) had raised levels of IgG ACA. In other reports ${ }^{1}{ }^{25}{ }^{32-34}$ this percentage varies between $76 \%{ }^{34}$ and $100 \% .^{32}$ In accordance with Branch $e t a l^{33}$ we found that there are clearly patients with discordant results for LAC and ACA assays. Depending on the LAC assay used we found that $11-31 \%$ of $\mathrm{LAC}$ positive patients were IgG ACA negative and that $54-65 \%$ of IgG ACA positive patients did not have LAC. Also, two 
out of 12 patients with medium or high IgG ACA levels were negative in all LAC assays. In other reports ${ }^{1} 62532-34$ the prevalence of a negative ACA assay in the presence of LAC varies between $0 \%{ }^{32}$ and $42 \%,{ }^{34}$ and of a negative LAC assay in the presence of IgG ACA between $17 \%{ }^{32}$ and $73 \% .^{25}$ These data clearly indicate that equation of LAC and ACA should be prevented. If the fact that cardiolipin is only a minor constituent of the platelet membrane is taken into account, our finding of a strong correlation between LAC and the presence of thrombocytopenia and the absence of such a relation between IgG ACA and thrombocytopenia supports suggestions made by others ${ }^{33}$ that other negatively charged phospholipids (e.g., phosphatidylserine) constitute the reactive epitope for antibodies detected with a coagulation assay. In addition, the discordant effect of prednisone on LAC and on IgG ACA levels, which was previously described by us, ${ }^{25}$ supports this notion.

The absence of a relation between LAC and raised IgM ACA levels is in accordance with early ${ }^{36}{ }^{37}$ and recent ${ }^{521}$ reports, which indicate that LAC is almost always caused by IgG and only occasionally by IgM class antibodies directed against negatively charged phospholipids.

A comparison of the sensitivity, specificity, and detection rate of the anti-PL antibody assays with respect to a history of thrombosis or fetal loss and the presence of thrombocytopenia showed that three of the LAC assays (PTT-HB, PL dilution, and the KCT) are superior to PTT-st or the ACAELISA. Higher specificity of LAC compared with ACA was also found by Petri et al, ${ }^{25}$ who used the Russell viper venom time to define LAC. In contrast, in a prospective study, Lockshin et al found ACA superior to LAC for prediction of fetal distress or death. ${ }^{38}$ By raising the cut off levels in the ACAELISA we could increase the specificity of this assay to $93 \%$, but just like others ${ }^{32}$ we found this was always accompanied by a severe drop in sensitivity $(\leqslant 30 \%)$.

Harris $e a^{32}$ reported, for ACA levels more than 5-6 SD above the mean control level, values for sensitivity, specificity, and detection rate that are comparable with those found by us with any of three LAC assays. Unfortunately, these authors did not include the LAC assay in their analysis. The discrepancies between our studies with respect to the value of the ACA assay are difficult to explain. Sera exchanged between our laboratories were concordantly classified as negative, low, medium, or high positive for ACA. The total number (111 $v$ 121) of patients, their age, and the number of patients with a history of fetal loss (19 v 14) are about the same in both studies, but the number of patients with a history of thrombosis is quite $\frac{\text { 으. }}{\text {. }}$ different $(26 v 60)$.

Although the availability of laboratory tests that $\stackrel{\overrightarrow{\vec{s}}}{\overrightarrow{2}}$ have a sensitivity of about $50-75 \%$ and a specificityo of about $80-85 \%$ towards thrombosis and fetal loss 흘 can indeed be regarded as useful for the characteris- $\frac{\bar{c}}{\sigma}$ ation of a particular subset of patients, prospective $\stackrel{\mathbb{Q}}{\Omega}$ studies will have to confirm and extend these findings before adequate therapeutic regimens can $\rightarrow$ be advocated for patients with anti-PL antibodies. This is strengthened both by data from a recent $\overrightarrow{\vec{\omega}}$ prospective study on 50 pregnant patients with SLE, $\stackrel{\circ}{\circ}$ which showed that with raised ACA levels or increased (A)PTT values, respectively $25 \%$ or $50 \%$ of the pregnancies resulted in live births, ${ }^{34}$ and by. the follow up of two of our patients who have had $\dot{\omega}$

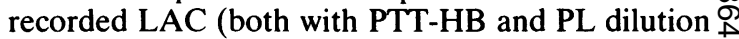
methods) for at least 10 years but never had thrombosis.

In conclusion, our data show that a panel of LAC $\overline{3}$ assays (PTT-HB; PL dilution; KCT) is useful for the detection of lupus patients with thrombosis, fetal $\vec{\bullet}$ loss, and/or thrombocytopenia, whereas the ACA $\infty_{\infty}^{\infty}$ assay is insufficiently specific for this purpose.

This work was supported by a grant (85 CR 46) from the Nederlandse Vereniging voor Reumabestrijding.

\section{References}

1 Harris E N, Gharavi A E, Boey M L, et al. Anticardiolipin $\overrightarrow{\overline{\bar{O}}}$ antibodies: detection by radioimmunoassay and association with thrombosis in systemic lupus erythematosus. Lancet 1983; ii: $1211-4$.

2 Derksen R H W M, Kater L. Lupus anticoagulant: revival of an? old phenomenon. Clin Exp Rheumatol 1985; 3: 349-57.

3 Feinstein D I. Lupus anticoagulant, thrombosis and fetal loss. N Engl J Med 1985; 313: 1348-50.

4 Derksen R H W M, Bouma B N, Kater L. The striking association between lupus anticoagulant and fetal loss in systemic lupus erythematosus. Arthritis Rheum 1986; 29: 695-6. O

5 Lechner K, Pabinger-Fasching I. Lupus anticoagulants and thrombosis. Haemostasis 1985; 15: 254-62.

6 Colaço C B, Male D K. Anti-phospholipid antibodies in syphilis and a thrombotic subset of SLE: distinct profiles of epitope $\frac{D}{O}$ specificity. Clin Exp Immunol 1985; 59: 449-56.

7 Mueh J R, Herbst K D, Rapaport S I. Thrombosis in patients N with the lupus anticoagulant. Ann Intern Med 1980; 92: 156-9. ఠ

8 Canoso $R$ T, Hutton R A, Deykin D A. Chlorpromazine- $N$ induced inhibitor of blood coagulation. Am J Hematol 1977; $2: \stackrel{\mathrm{N}}{183-91 .}$

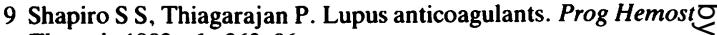
Thromb 1982; 6: 263-86.

10 Schleider M A, Nachman $R$ L, Jaffe E A, Coleman M. 들 A clinical study of the lupus anticoagulant. Blood 1976; 48: 499-509.

11 Boxer M, Ellman L, Carvalho A. The lupus anticoagulant. Arthritis Rheum 1976; 19: 1244-8.

12 Triplett D A, Brandt J T, Maas $R$ L. The laboratory $\vec{D}$ heterogeneity of lupus anticoagulants. Arch Pathol Lab Med 1985; 109: 946-51.

13 Green D, Hougie C, Kazmier F J, et al. Report of the working party on acquired inhibitors of coagulation: Studies of the "lupus" anticoagulant. Thromb Haemost 1983; 49: 144-6. 
14 Mannucci P M. Canciani M T. Meucci P. The varied sensitivity of partial thromboplastin and prothrombin time reagents in the demonstration of the lupus-like anticoagulant. Scand $J$ Haematol 1979: 22: 423-32.

15 Kelsey P R, Stevenson K J, Poller L. The diagnosis of lupus anticoagulants by the activated partial thromboplastin timethe central role of phosphatidyl serine. Thromb Haemost 1984; 52: $172-5$.

16 Thiagarajan P. Pengo V, Shapiro S S. The use of the dilute Russell viper venom time for the diagnosis of lupus anticoagulants. Blood 1986; 68: 869-74.

17 Triplett D A, Brandt J T, Kaczor D, Schaeffer J. Laboratory diagnosis of lupus inhibitors: a comparison of the tissue thromboplastin inhibition procedure with a new platelet neutralization procedure. Am J Clin Pathol 1983; 79: 678-82.

18 Rosove M H, Ismail M, Koziol B J, Runge A, Kasper C K. Lupus anticoagulants: improved diagnosis with a kaolin clotting time using rabbit brain phospholipid in standard and high concentrations. Blood 1986; 68: 472-8.

19 Alving B M. Baldwin P E, Richards R L, Jackson B J. The dilute phospholipid APTT: a sensitive assay for verification of lupus anticoagulants. Thromb Haemost 1985; 54: 709-12.

20 Exner T, Rickard $\mathrm{K} \mathrm{A}$, Kronenberg H. A sensitive test demonstrating lupus anticoagulant and its behavioural patterns. Br J Haematol 1978; 40: 143-51.

21 Branch D W, Rote N S, Scott J R. The demonstration of lupus anticoagulant by an enzyme-linked immunoadsorbent assay. Clin Immunol Immunopathol 1986; 39: 298-307.

22 Espinoza L R, Hartmann R C. Significance of the lupus anticoagulant. Am J Hematol 1986; 22: 331-7.

23 Koike T, Sueishi M. Funaki H. Tomioka H, Yoshida S. Antiphospholipid antibodies and biological false positive serological test for syphilis in patients with systemic lupus erythematosus. Clin Exp Immunol 1984; 56: 193-9.

24 Derue G J, Englert H J, Harris E N, et al. Fetal loss in systemic lupus: association with anticardiolipin antibodies. J Obstet Gynecol Neonatal Nurs 1985; 5: 207-9.

25 Petri M, Rheinschmidt M, Whiting-O'Keefe O. Hellmann D. Corash L. The frequency of lupus anticoagulant in systemic lupus erythematosus. Ann Intern Med 1987; 106: 524-31.
26 Tan E M. Cohen A S, Fries J F, et al. The 1982 revised criteria for the classification of SLE. Arthritis Rheum 1982; 25: 1271-7.

27 Hjort P, Rapaport S I, Owren P A. A simple specific one-stage prothrombin assay using Russell's viper venom in cephalin suspension. J Lab Clin Med 1955; 46: 89-97.

28 Rosner E, Pauzner R, Lusky A, Modan M, Many A. Detection and quantitative evaluation of lupus circulating anticoagulant activity. Thromb Haemost 1987; 57: 144-7.

29 Harris E N, Gharavi A E, Patel S P, Hughes G R V. Evaluation of the anticardiolipin antibody test: report of an international workshop held 4 April 1986. Clin Exp Immunol 1987; 68: 215-22.

30 Griner P F, Mayewsk R J, Mushlin A I, et al. Selection and interpretation of diagnostic tests and procedures. Ann Intern Med 1981; 94: 553-600.

31 Sturfelt G, Nived O, Norberg N, Thorstensson R, Krook K. Anticardiolipin antibodies in patients with systemic lupus erythematosus. Arthritis Rheum 1987; 30: 382-8.

32 Harris E N, Chan J K H, Asherson R A, Aber V R, Gharavi A E. Hughes G R V. Thrombosis, recurrent fetal loss, and thrombocytopenia. Predictive value of the anticardiolipin antibody test. Arch Intern Med 1986; 146: 2153-6.

33 Branch D W, Rote N S, Dostal D A. Scott J R. Association of lupus anticoagulant with antibody against phosphatidylserine. Clin Immunol Immunopathol 1987; 42: 63-75.

34 Lockshin M D, Quamar T, Druzin M, Goei S. Antibody to cardiolipin, lupus anticoagulant, and fetal death. $J$ Rheumatol 1987; 14: $259-62$

35 Derksen R H W M, Biesma D, Bouma B N, Gmelig Meyling F H J, Kater L. Discordant effects of prednisone on anticardiolipin antibodies and the lupus anticoagulant. Arthritis Rheum 1986; 29: 1295-6.

36 Yin E T, Gaston L W. Purification and kinetic studies on a circulating anticoagulant in a suspected case of lupus erythematosus. Thrombosis et Diathesis Haemorrhagica 1965; 14: 88-114.

37 Lechner K. A new type of coagulation inhibitor. Thrombosis et Diathesis Haemorrhagica 1969; 21: 482-99.

38 Lockshin M D. Druzin M L. Goei S, et al. Antibody to cardiolipin as a predictor of fetal distress or death in pregnant patients with systemic lupus erythematosus. $N$ Engl J Med 1985; 313: 152-6. 